\title{
Innovative Planning and New-Type Urbanization in China: The Case of Wuxi City in Jiangsu Province
}

\author{
Wenwei Zhu ${ }^{1}$, Prosper Bernard Jr. ${ }^{2}$, Michel Plaisent ${ }^{3}$, James Ming-Hsun Chiang ${ }^{4}$ \\ ${ }^{1}$ City Development Research Institute of China, Beijing, China \\ ${ }^{2}$ Department of Political Science and Global Affairs, City University of New York, New York, USA \\ ${ }^{3}$ Department of Management and Technology, University of Quebec in Montreal, Montreal, Canada \\ ${ }^{4}$ Research Center of Government Management, Peking University, Beijing, China \\ Email: prosper.bernard@aol.com
}

Received 5 September 2014; revised 15 October 2014; accepted 28 November 2014

Copyright (C) 2014 by authors and Scientific Research Publishing Inc.

This work is licensed under the Creative Commons Attribution International License (CC BY).

http://creativecommons.org/licenses/by/4.0/

(c) (i) Open Access

\begin{abstract}
Urbanization has been a transformative process in 21st century China. This paper seeks to examine the process of urbanization in Wuxi City, Jiangsu Province, specifically to identify the ways in which Wuxi City has engaged in new-type urbanization-an innovative pattern of urban development that seeks to integrate urban and rural development, achieve environmental sustainability, and provide for the wellbeing of an urbanized citizenry. The City's model has potentially important reference value for other cities and towns in developed areas of China that are in the process of fashioning their own innovative pattern of urbanization.
\end{abstract}

\section{Keywords}

China, Innovative Planning, New-Type Urbanization, Wuxi City

\section{Introduction}

Urbanization in China is characterized by ongoing efforts to balance urban and rural development, promote urban-rural integration, facilitate interaction between industries and cities, and achieve urban development that is conducive to ecological sustainability and livable cities. The core of the concept of new-type urbanization (NTU) is the idea that urbanization should not be conducted at the expense of agriculture and environment. Further, NTU is designed to achieve integration of urban and rural infrastructures and equalization of public services, economic and social development, and common prosperity between urban and rural areas.

How to cite this paper: Zhu, W., Bernard Jr., P., Plaisent, M., \& Chiang, J. M.-H. (2014). Innovative Planning and New-Type Urbanization in China: The Case of Wuxi City in Jiangsu Province. Current Urban Studies, 2, 307-314.

http://dx.doi.org/10.4236/cus.2014.24029 
During the period time between the Ninth Five-Year Plan (1996-2000) and the Eleventh Five-Year Plan (2006-2010), urbanization proceeded at an accelerated pace in China. As urban areas in developed areas have modernized, a large number of surplus rural labor has been absorbed by them. As the development of such cities enters into high-speed, both social dislocation and socioeconomic improvement have occurred (Chen, 2009; Wu \& Zhang, 2007). Thus, urban planners face several challenges: What kind of measures should they undertake to guarantee orderly and rational development of urban areas? How should social economic development and regional competitive advantages be fostered? What should be done to ensure sustainable development of resources?

\section{Understanding the Process of Urbanization in China}

New-type urbanization in China includes three integral components. First, urbanization is consistent with the trend of the times and is a normal step in a country's modernization and efforts to boost its international competitiveness. Second, urbanization needs to be promoted in a way that drives sustainable development of the national economy and helps society to bridge the chasm between social classes. Finally, promoting urbanization offers unique opportunities to address and fix existing economic and social problems. The promotion of urbanization in China should also facilitate the development of regional economies. In particular, urbanization should lead to the establishment of an effective social safety regime that supports the process of developing integrated regional economies. Further, urbanization should accommodate the development of metropolis clusters and small towns' modernization in which rational specialization and synergistic complementarities emerge across economic spaces (Wang, 2008).

Figure 1 tracks the urbanization rate during six five-year plans. The black (A) trend line corresponds to the rate at the beginning of each five-year period while the red (B) trend line measures the rate at the end of each period. Overall, the beginning-end gap is wider for the last three five-year periods than for the first three timeframes, in other words, urbanization has accelerated over time. This is clearly illustrated in Figure 2. The data show that since 1996, urbanization in China has seen gradually higher average annual urbanization rates. During the period between the Ninth Five-Year Plan (1996-2000) and the Eleventh Five-Year Plan (2006-2010), the annual average urbanization rate has ascended by 1.43\%, 1.35\% and 1.39\% respectively, far higher than the increases in urbanization rates during the period between the Sixth Five-Year Plan (1981-1985) and the Eighth Five-Year Plan (1991-1995).

Many observers have claimed that China's urbanization development is unsustainable. However, cross-national analysis reveals that China's urbanization level places it in the relatively low intensive country cluster. As Figure 3 and Figure 4 illustrate, China's recent urbanization rates are below several countries-most notably South Africa and Malaysia whose urbanization now encompasses more than half of their society. According

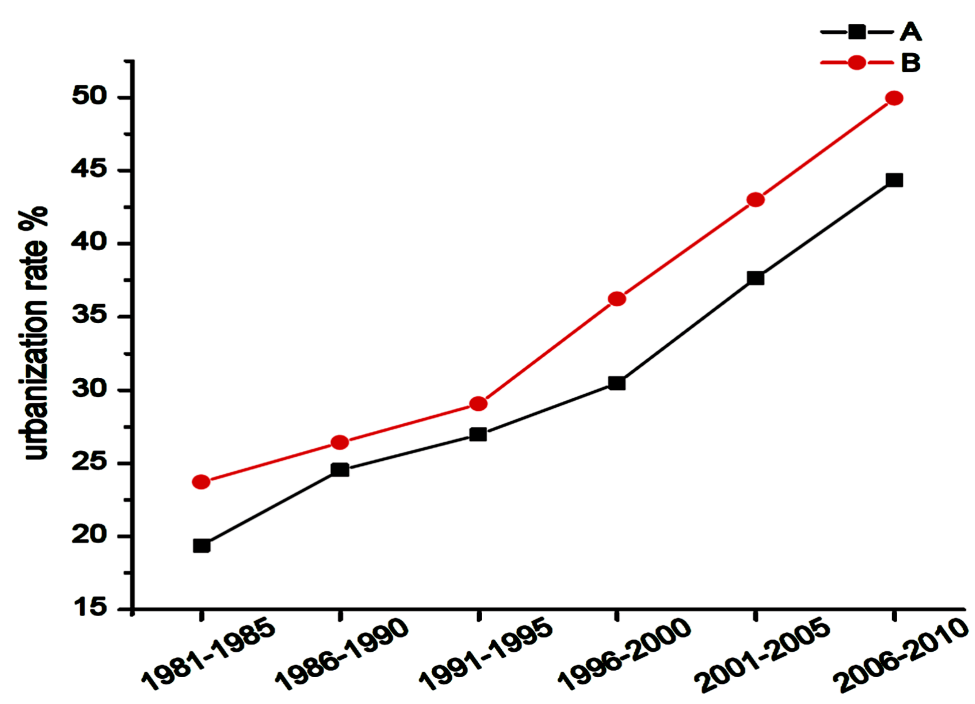

Figure 1. Urbanization rate (\%) between the Sixth Five-Year Plan and the Eleventh Five-Year Plane. Source: Ba \& Yang, 2013. 


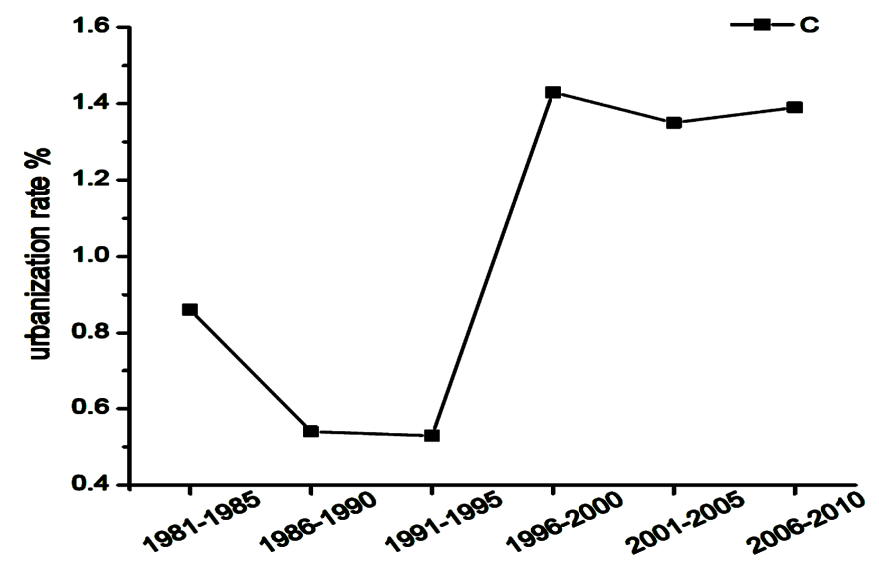

Figure 2. Annual average urbanization rate (\%) between the Sixth Five-Year Plan and the Eleventh Five-Year Plan. Source: Ba \& Yang, 2013.

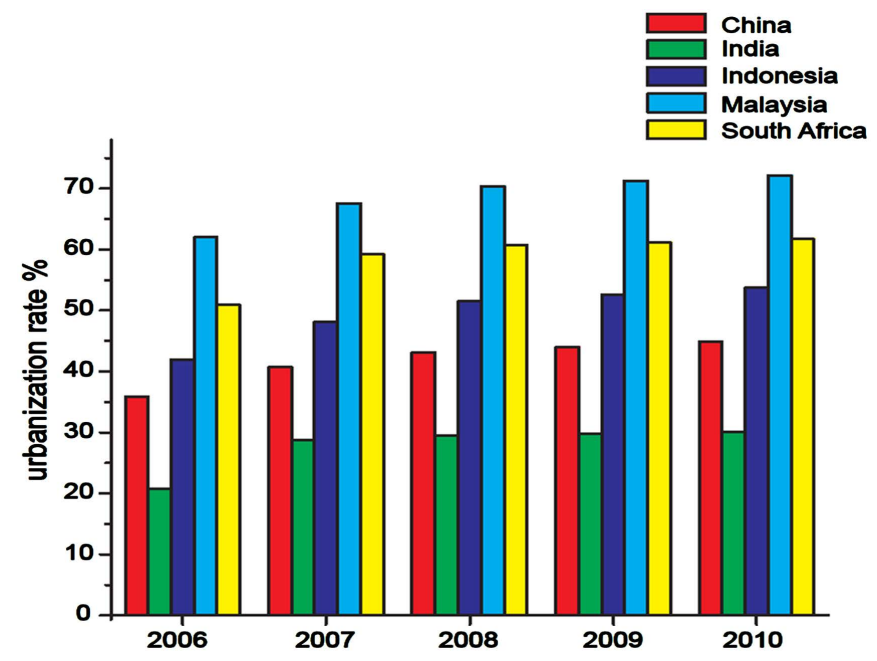

Figure 3. Statistic data of urbanization rate (\%) of some countries between 2006 and 2010. Source: Ba \& Yang, 2013.

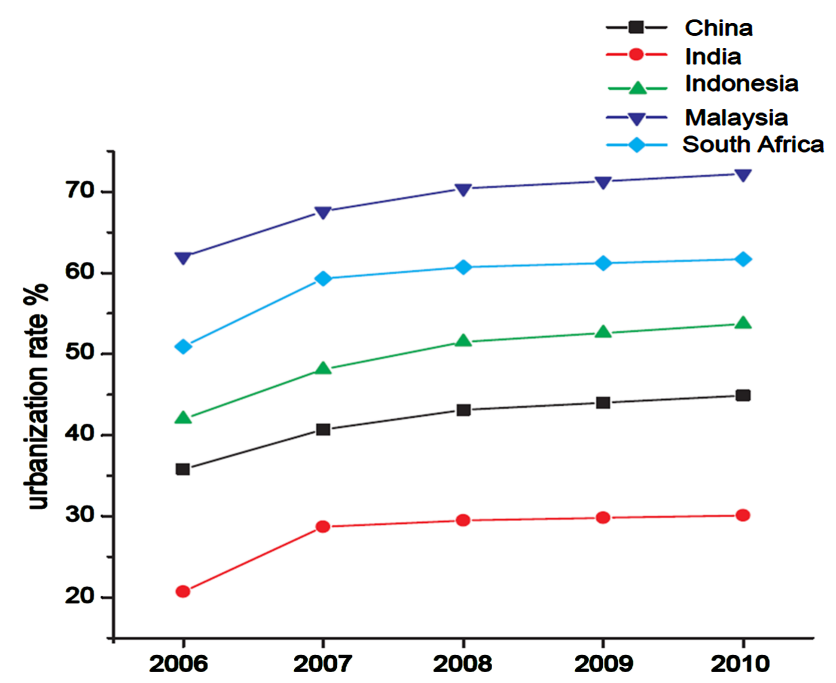

Figure 4. Development tendency of urbanization rate (\%) of some countries between 2006 and 2010. Source: Ba \& Yang, 2013. 
to the data, the domestic reforms that China has implemented over the past 30 years has helped bring the country's urbanization rate increasingly closer to the world average level. However, population urbanization rate in China is only about $35 \%$ if we assess urbanization according to household registration, which is far lower than the average level of $52 \%$ in the world. This is because China's urbanization numbers have been calculated based on population of permanent residents in cities and towns plus the 160 million migrant workers.

As urbanization in China continues to intensify, public officials will face a number of difficult challenges. Among them are: How to make ordinary people living in rural and urban areas find consistent income sources and improve their standard of living? How to develop an urban infrastructure that caters to the needs of an aging population? How to address issues relating to medical treatment, education, health care, and social security support? Overall, these and other challenges point to one common factor: How should China ensure innovative urbanization - that is urban development that is socially and economically sustainable?

\section{Urbanization in Wuxi City: An Example of Innovative Urbanization}

Wuxi City, "Xi" for short, was known as Liangxi and Jinkui in ancient times and is recognized as the "Pearl of Taihu Lake". It is one of the oldest places of habitation south of the Yangtze River, with a history dating back to the last years of Shang Dynasty 3000 years ago. Wuxi City is located in the hinterland of Yangtze River Delta Plain in the southern part of Jiangsu Province and serves as a transit hub in the Taihu Lake Basin with the Beijing-Hangzhou Grand Canal flowing across the city. With the Yangtze River to its north and Taihu Lake to its south, it adjoins Suzhou in the east and borders Changzhou in the west creating the Su-Xi-Chang Metropolitan Area. Wuxi City has a population of 4,679,600 and administers 2 county-level cities and 7 districts including 32 villages and towns, covering a total area of 4627.47 square kilometers.

In 2013, the gross regional domestic product of Wuxi City reached RMB 688,015,000,000 yuan positioning it in second place in Jiangsu Province and in ninth place nationwide in terms of economic size. In addition, its per capita GDP reached RMB 107,400 yuan (USD 17,000) making it the first city to achieve the goal of RMB 100,000 yuan per capita GDP set by Jiangsu Province. In 2013, the city ranked third in Jiangsu Province in terms of general budget revenue for local finances amounting to RMB 61.5 billion yuan. Further, Wuxi City ranked seventh in terms of total industrial output value, eighth for total export-import volume, and ninth for gross regional domestic product among large and medium-sized cities nationwide. It is one of the 34 nationwide main port hubs and also one of the 54 highway transportation centers. Wuxi City's economic importance is further illustrated by the fact that along with its distinctive tourism experience, it produces popular crops including tea, flowers, nursery stock, and medicinal plants, covering a plant area of 226,000 mu (Ba \& Yang, 2013).

According to the latest statistical data the total population in mainland China in 2013 was 1,360,720,000 of which 731,110,000 were part of the urban resident population (53.7\%). Based on data from different provinces, the urbanization rate of 18 Chinese provinces exceeds $50 \%$ and 13 provinces have rates that are higher than the national average urbanization level. The urbanization rate of Wuxi City (57\%), a third-tier city in China, has exceeded the national average level, and its urbanization quality ranks 14th nationwide. Figure 5 and Figure 6 compares the urbanization rates of Wuxi relative to national and world levels. While the rate of increase is similar between China and Wuxi, what is clear is that Wuxi's rate has consistently been higher than the national level. Further, as Figure 6 shows, it is only in 2012 that Wuxi's rate and in 2013 that China's rate surpassed the world's average urbanization rate.

Central to Wuxi City's rapid urbanization is the fact that the city has undertaken comprehensive upgrading of business support, transport infrastructure, public service facilities, housing construction, and environmentally friendly practices. During the period of the "Twelfth Five-Year Plan" (2011-2015) Wuxi City has branded itself as an "Eco-city, tourism and modern services city, high-tech industrial city and livable city". A key component of this model has been to strengthen regional coordination and balance urban and rural development, efforts deemed feasible given the City's ideal geographical location. Wuxi City has been a driver of regional development, and, by building 33 functionally oriented urban complexes, the city has become a cultural, social, entertainment, and commercial hub.

During the period between 2011 and 2015, urban-rural integration in Wuxi City has led to industry amalgamation and merging of work systems, policy planning systems and social security systems. The motto "Cities Supporting Rural Areas and Industry Nurturing Agriculture" has been put into effect by establishing "Five Major Agricultural Clusters" and "Top Ten Park-groups". These efforts have contributed to the creation of extensive networks joining urban and rural centers. 


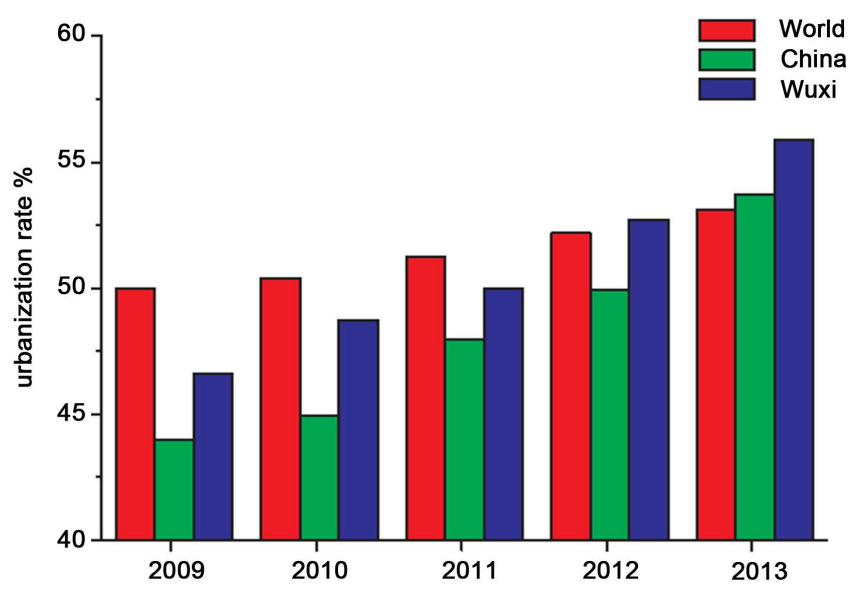

Figure 5. Average urbanization rate (\%) of the world, China and Wuxi City between 2009 and 2013. Source: Ba \& Yang, 2013.

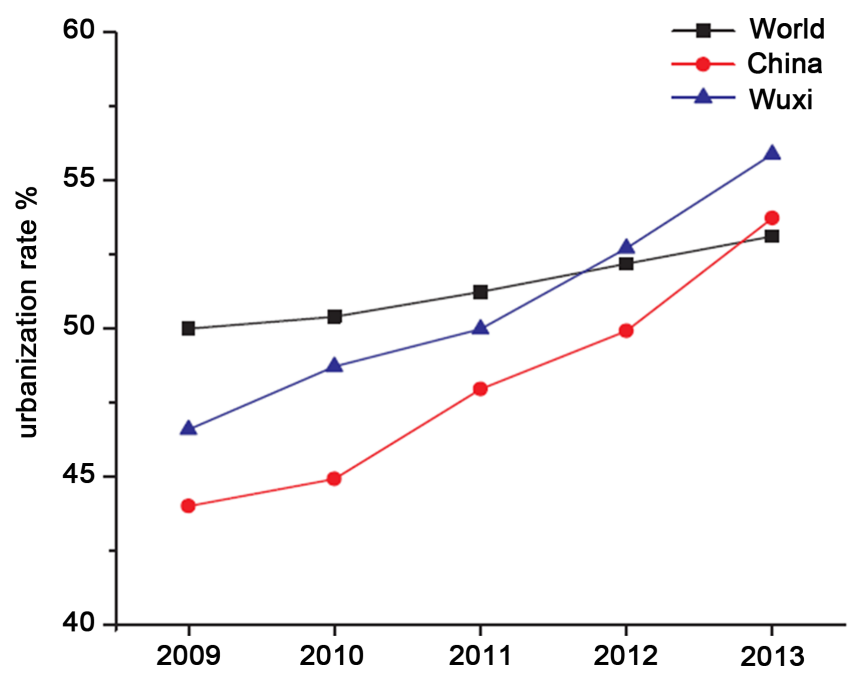

Figure 6. Development tendency of average urbanization rate (\%) of the world, China and Wuxi City between 2009 and 2013. Source: Ba \& Wang, 2013.

As it develops urban and rural areas, Wuxi City also has invested heavily in modernizing its transportation network. The City plans to construct 3 expressways, 10 highways, 7 fast roads with the length of $90 \mathrm{~km}$, and 108 primary and secondary trunk roads with the length of $459 \mathrm{~km}$. Further, the City is constructing 14 bus hub stations and 13 bus maintenance stations, and is gradually integrating the transport hub for Wuxi Railway Station, inter-city railway hub for Huishan Stop, Wuxistation hub for Beijing-Shanghai High-speed Railway, and airport hub for Wuxi Airport. It has spared no efforts to build a low-carbon transportation system and expand the rail transitsystem in an attempt to ease city traffic flows and reduce pollution emission. Wuxi City has built three rail lines with a combined length of 100 kilometers and the rail network has a total of 72 stations to accommodate its users, thus significantly alleviating urban traffic pressures.

The impact of Wuxi City's infrastructure modernization has been twofold. First, as the map below illustrates, the towns of Yixing (in the southwestern part) and Jiangyin (in the northeastern part) have become increasingly connected to the city center as a result of the expansion of the transportation network, thus facilitating economic integration of rural and urban areas. Second, the City's role as a commercial hub has been enhanced significantly due in part to the transition into higher value-added manufacturing activities—such as precision machinery, electronic information, mechanical and electrical integration, chemicals, and bio-pharmaceuticals-and in part to improvements in the transportation system that connects the City to neighboring regional economies such as Shanghai. 


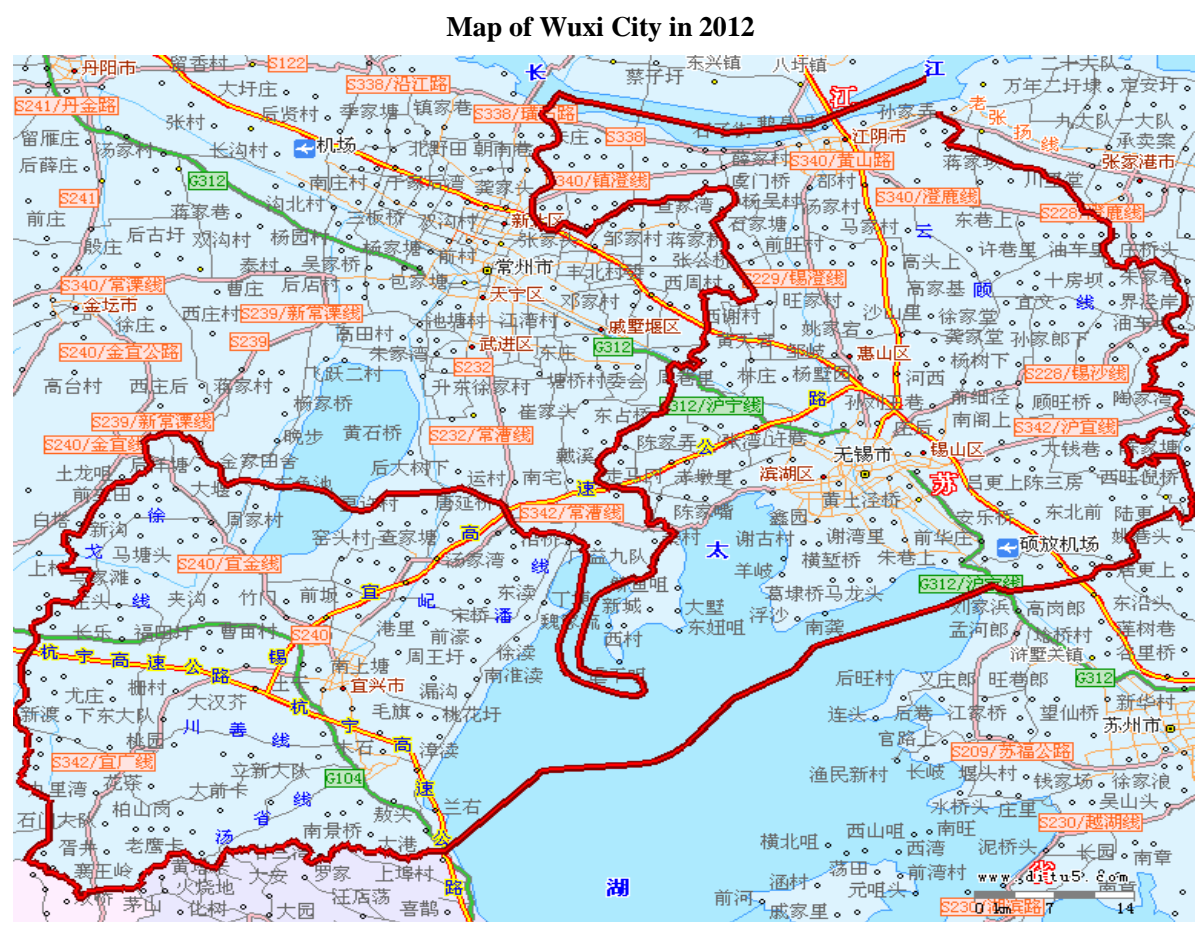

\section{Ecologically Friendly Urban Development}

In an effort to become an internationally renowned eco-city, Wuxi City has focused its attention on ecological protection as it expands the new city region and upgrades the old city region. The City-which the Ministry of Environmental Protection has recognized as an Eco-City since 2009-currently has 75 parks in the downtown area, including 17 ecological parks (5 newly built ones), such as Liangtang River Wetland Park, Xingtang River Wetland Park, Wanshandang Wetland Park, Pailou Ecological Park and Xiyanchitou Ecological Park. Furthermore, there are 15 municipal-level comprehensive parks (3 newly built ones), 26 district-level comprehensive parks (15 newly built ones) and 17 theme parks (7 newly built ones) (Zhou, He, \& Williams, 2012). Within the next three years city officials plan to build 23 parks_-7parks are under construction and 16 parks will be built. Overall, it is expected that the greening rate in Wuxi City will reach $41 \%$, the green coverage rate will rise to 46\%, and per capita park green space area will reach 16 square meters by 2015 .

Wuxi City is one of the few Chinese cities to have dedicated vast resources and time to city park development-a feat attested by the fact that it was named the first "National Forest City" in Jiangsu province in 2009. According to plans, there will be 31 comprehensive parks with an area of over 10 hectares in the downtown area by 2020, which will significantly boost the City in its ranking on the national ecological garden city index. What is more, according to a Wuxi Low-Carbon City Development Strategic Planning document released in 2010, the City is aiming to reduce carbon intensity by 45\% by 2020 (Zhou, He, \& Williams, 2012).

\section{Urban-Village Reconstruction and Improvement of Public Service Facilities}

As Wuxi City undertakes construction it has adhered to the principles of a "livable city" and balanced urban and rural public service improvement. During the Twelfth Five-year Plan the City has committed itself to applying the highest standards in designing, planning and building affordable housing units. According to incomplete statistics, Wuxi City plans to construct three highly standardized international communities; ten livable demonstration community; 90,000 square meters of affordable housing (including Panpoqiao and Xingda Foamed Plastic Factory plot and Youth Commune); and 31,700,000 square meters of placement housing (including Donggang Placement Housing, Chunhe Dongyuan Placement Housing and Ehu Placement Housing). Parts of the old city (4 million square meters) will undergo reconstruction with the aim of creating a modern urban space that enhances the quality of life. Finally, Wuxi City is planning to build a batch of public service facilities that will offer a variety of public services such as education, vocational training, sports and health care. 
All in all, in order to achieve integrated development and promote transformation of urban and rural areas, the Twelfth Five-year Plan has concentrated on a three-dimensional space development pattern of the central urban area, new city region, and external towns clusters. Additionally, the development of public service facilities and affordable housing units combined with the application of ecologically friendly practices and sound urban-rural planning standards has enabled the City to gradually bridge the gap between urban and rural areas and build a new type of synergy between the two spaces.

\section{The Rise of Innovative Patterns of Urbanization in China}

This case study analysis of Wuxi City identifies a number of key features associated with an innovative pattern of urbanizations. The first component is urban development strategizing and industrial planning. Strategizing and planning, in particular, involve construction system planning, urbanization investment planning, and urbanization social management system - all of which should be undertaken with an eye on fostering institutional complementarity. Hence, this can be referred to as overall strategy planning and industries planning. The overall strategy planning and industries planning should foster "six-integration"- namely, integration of urban and rural planning, integration of urban and rural industries, integration of urban and rural market systems, integration of urban and rural infrastructures, integration of urban and rural public services, and integration of urban and rural management systems. Additionally, the process of economic modernization should promote "two-combination"namely, flexibilization and mobility of rural labor force combined with full employment, and land reform combined with financial innovation. This is a central component of new-type urbanization (Li \& Wu, 2014).

Second, the implementation of urbanization plans should attach importance to how to solve problems relating to farming, agriculture, and rural areas (Luo, Shen, \& Gu, 2014). The ideal way to address these challenges is by fostering urbanization, industrialization, information technology, and modernization of agriculture. Urbanization not only improves industrialization and strengthens urban economic power, but also creates demand for agricultural products. Cities support the countryside, absorb rural labor force, promote agricultural scale operation and thus increase farmers' income earnings. New-type urbanization development is not about destroying rural areas and reducing agricultural production, in other words; rather it is about converting farmers into workers or new type farmers enjoying the full benefits of urban citizenry, thus achieving a kind of "urbanization for the people". New-type urbanization also highlights a new collective public awareness-that is, a need for resource intensive conservation and ecologically friendly development.

Third, urbanization demands that no effort be spared to develop urban infrastructure; set up and improve public service system; build commercial and affordable housing; and offer employment and vocational skills training. To meet these large investment needs financing mechanisms are required, featuring multi level sources, diversification and marketization (Liu, 2014). Cost sharing among multiple agents such as government, enterprises and individuals is imperative. Further, city governments' fiscal capacity must be strong enough to sustain innovative-based urban development. Financial services development must include the following aspects. First, local financing platforms should be created which actively promote asset securitization, allow local governments to issue bonds, and develop urban and real estate trust funds. Second, it should create a multi-level financial system involving the central governments, local governments, financial institutions, central enterprises, and non-governmental organizations. Third, it should liberalize capital markets and attract private capital and even external capital to participate in urbanization (Luo, Cheng, \& Wang, 2014).

\section{Conclusions}

New-type urbanization should be people-oriented and integrate manufacturing with towns and financial services with manufacturing according to each area's politics, economy, culture, and unique historical characteristics. New-type urbanization should be sensitive to the historical importance of certain spaces, such as Wuzhen Town in Zhejiang Province and Fenghuang in Hunan Province. As to cities with more well-known tourist and cultural industries, new-type urbanization should be tailored to suit those cities' unique qualities. Urbanization in China confronts two challenges: How to balance local economic development and ecological sustainability and, how to develop livable spaces that enhance the quality of life of a growing urban citizenry.

In sum, cities across China have to figure out how best to promote an innovative pattern of urbanization for their cities. At present, new-type urbanization in China has attracted much scholarship and public policy attention. Future studies should focus on the following questions: How should new-type urbanization be funded? 
How should stakeholders participate in it? How should industries contribute to the progression of new-type urbanization? The answers to these questions will offer practical guidance for cities across China as they chart their own innovative pattern of urbanization.

\section{References}

Ba, S., \& Yang, X. (2013). Great Transformation Urbanization: Financial Perspective. Xiamen: Xiamen University Press.

Chen, X. (2009). Push-Pull Model and Empirical Analysis of Rural Labor Transfer in China. Science Technology and Industry, 9, 12-19.

Li, Y., \& Wu, F. (2014). Reconstructing Urban Scale: New Experiments with the "Provincial Administration of Counties” Reform in China. The China Review, 14, 147-174.

Liu, K. (2014). Transcript: Press conference on New Urbanization Plan. http://china.org.cn/china/2014-03/19/content_31836248_4.htm

Luo, X., Cheng, Y., Yin, J., \& Wang, Y. (2014). Province-Leading-County as a Scaling-Up Strategy in China: The Case of Jiangsu. The China Review, 14, 125-146.

Luo, X., Shen, J., \& Gu, C. (2014). Urban and Regional Governance in China: Introduction. The China Review, 14, 1-10.

Wang, F. (2008). Urban Development of China since the Mid-1980s. Population \& Economic, 5, 8-12.

Wu, F., \& Zhang, J. (2007). Planning the Competitive City-Region: The Emergence of Strategic Development in China. Urban Affairs Review, 42, 714-740. http://dx.doi.org/10.1177/1078087406298119

Zhou, N., He, G., \& Williams, C. (2012). China’s Development of Low Carbon Eco-Cities and Associated Indicator Systems. Berkeley, CA: Ernest Orlando Lawrence Berkeley National Laboratory. LBNL-5873E. 
Scientific Research Publishing (SCIRP) is one of the largest Open Access journal publishers. It is currently publishing more than 200 open access, online, peer-reviewed journals covering a wide range of academic disciplines. SCIRP serves the worldwide academic communities and contributes to the progress and application of science with its publication.

Other selected journals from SCIRP are listed as below. Submit your manuscript to us via either submit@scirp.org or Online Submission Portal.
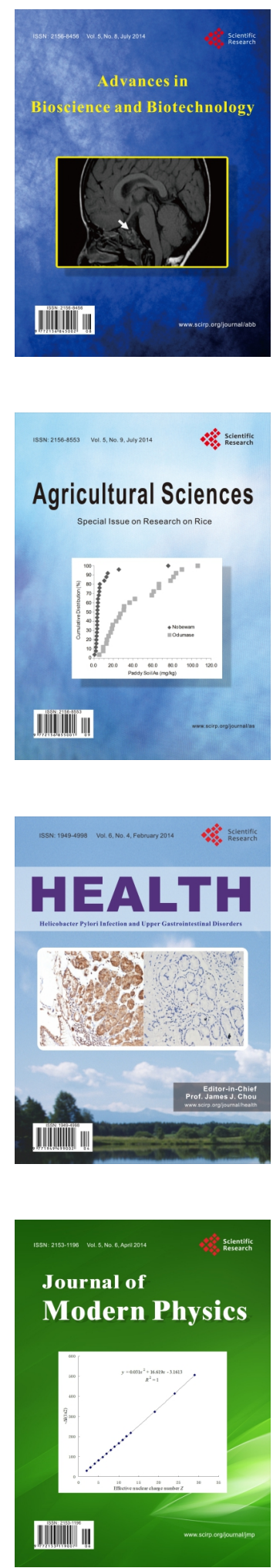
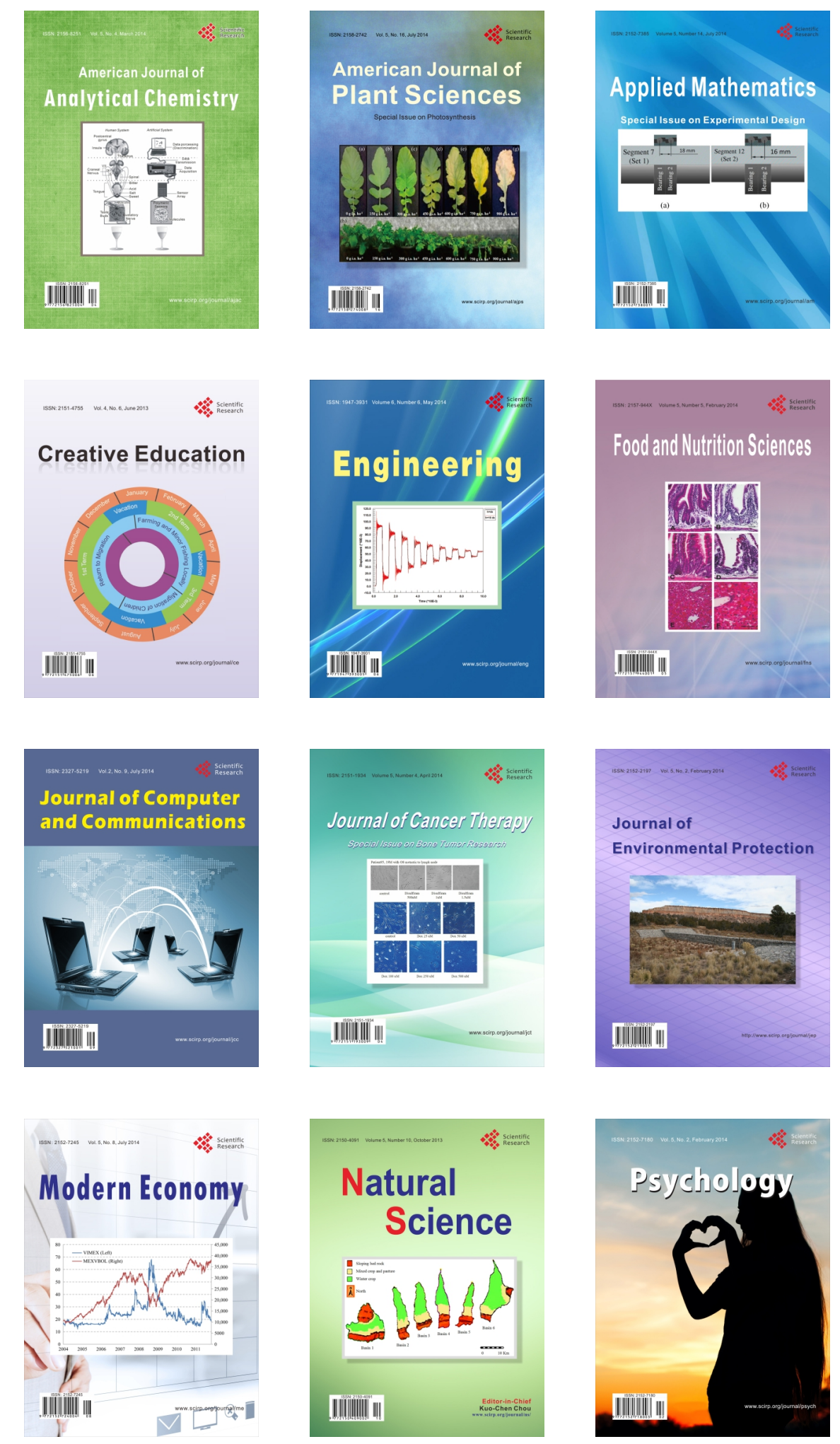